\title{
Design, Modelling and FEM Analysis of Excavator Arm
}

\author{
Pravin Yerwal ${ }^{1}$, Pooja Thawal ${ }^{2,}$ Sheela Bansode ${ }^{3}$, Vishakha Deore ${ }^{4}$, Dr.Anil Sahu ${ }^{5}$ \\ ${ }^{1}$ UG - Mechanical Engineering, G.H.Raisoni College of Engineering and Management, Pune, Maharashtra \\ ${ }^{2}$ UG - Mechanical Engineering, G.H.Raisoni College of Engineering and Management, Pune, Maharashtra \\ ${ }^{3}$ UG - Mechanical Engineering, G.H.Raisoni College of Engineering and Management, Pune, \\ ${ }^{4}$ UG - Mechanical Engineering, G.H.Raisoni College of Engineering and Management, Pune, Maharashtra \\ ${ }^{5}$ Professor, Mechanical Engineering, G.H.Raisoni College of Engineering and Management, Pune, Maharashtra
}

\begin{abstract}
Excavators are intended for excavating rocks and soils. It consists of four link members: the bucket, the stick, the boom and the revolving super structure (upper carriage). Excavator arm is one of the most important attachments of an excavator. The excavators arm has to work reliable under many different working conditions with high amount of load. Hence it is required to design an equipment which has maximum reliability and minimum weight, maintaining all the factors of safety under all working and loading conditions. The excavator mechanism must work reliably under unpredictable working conditions. Thus, it is very much necessary for the designers to provide not only an equipment of maximum reliability but also of minimum weight and cost, keeping design safe under all loading conditions. The aim is to design and develop an excavator which will be focused on the rigid and flexible arm-boom-bucket linkage called "Design and Development of Excavator Arm using FEM Analysis ". A detailed inspection has been carried out by finite element analysis (FEA) using the ANSYS software to observe and examine the stress developed in the arm for all design considerations. At the end, the stress developed due to working load for every single design has been observed and examined to check whether they are safe or not. The results of this research and observation are that the weight of the excavator arm can be modified by making some sort of design and material changes, keeping the all Factor of Safety as they were. Excavators are earth moving equipment and the main component to get the work done is its function is arm, which directly affect the working performance and reliability of the excavator. However, using the finite element analysis (FEA) method for Design and structural analysis of the excavator arm is required and mandatory for the structural design of the arm.
\end{abstract}

Keywords: Excavators, Excavator arm, unpredictable working conditions, FEM Analysis, ANSYS software, safe limit

\section{INTRODUCTION}

Primarily, the excavators are used to excavate below the rough surface of the ground on which the machine rests and load it into conveyors, trucks or tractor. The Excavators made up of four connecting members named as the bucket, the stick, the boom and the base structure rotating or revolving super structure (upper carriage). Due to some certain working conditions, the excavator parts are subjected to working under high load conditions. The excavator's mechanism must work reliably and efficiently under unpredictable or uncertain working conditions. Poor strength properties of the excavator parts like boom, arm and bucket limit the life expectancy of the excavator. Generally, the excavator always works under cyclic motion during excavation process. Due to this continuous repetitive nature of work, cyclic stresses are developed in the parts of every attachment. High level of stresses can cause the internal damage of critical parts of the excavator and it will adversely be affecting on productivity of machine. Now a days, the weight factor is major concern while examining and designing the machine components. That's why, for reducing the overall cost as well as smoothing and increasing the softness in the performance of machine, the optimization is required for sure.

Thus, it is very much necessary for the designers to provide not only an equipment of maximum reliability but also of minimum weight and cost, keeping design safe under all loading conditions. Finite Element Analysis (FEA) is the most powerful technique in strength calculations of the structures working under known load and boundary conditions. A detailed investigation has been carried out by finite element analysis using ANSYS software to understand the stress developed in the arm for all design considerations.

\section{EXPERIMENTAL METHODS OR METHODOLOGY}

As per as the digging task is considered repetitive in nature and during this task, all entire link mechanism working under the dynamic conditions. If the damage rate goes higher then it will lead to higher maintenance and higher downtime (the lower machine ability) which subtract from the net working capacity of the machine. The first arm, which is close 


\section{International Advanced Research Journal in Science, Engineering and Technology}

Vol. 8, Issue 6, June 2021

DOI: $10.17148 /$ IARJSET.2021.8642

to the control cabin and the axis of rotation of the machine has a length of 6.9 meter. While the second arm, the one with the bucket is attached has a length of 3.6 meter.

\section{A. Analysis of existing model}

The machine at the base of this study is a commercial excavator produced by the CAT company whose acronym is $336 \mathrm{~F}$. This machine has a motor with a power of $234 \mathrm{~kW}$ and an operating weight of $40800 \mathrm{~kg}$. The main dimensions of the excavator are shown in Figure 1. The machine is equipped with two arms. The first one close to the control cabin and the axis of rotation of the machine has a length of $6.9 \mathrm{~m}$ while the second arm, the stick, the one to which the bucket is attached, has a length of $3.6 \mathrm{~m}$.

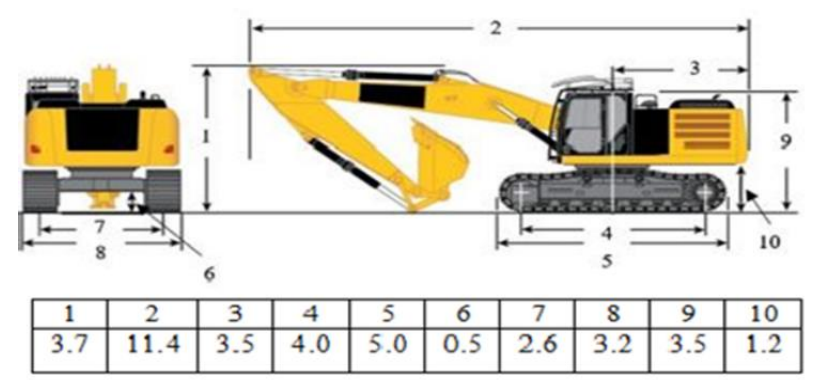

Fig.1 Excavator Dimensions

\section{B. Reverse engineering of existing model.}

The Reverse engineering is the design process in which a product is examined and analyzed using a physical part as a starting point. During the design process as per a new product is considered, modeling can be used in context to test, examine, evaluate and validate the conceptual design. This process requires some sort of modifications in the original design. For that reason, the reverse engineering could be considered as a important solution for innovating the original product design.

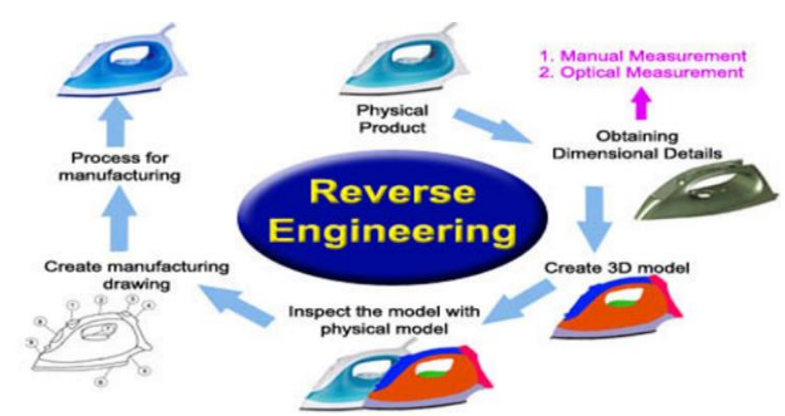

Fig. 2 Reverse Engineering.

\section{Generation of 3D model in CATIA V5R19 software}

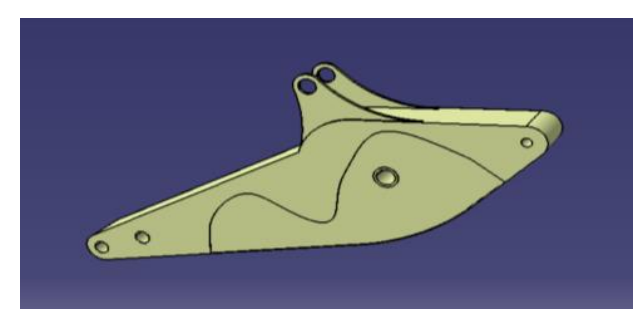

Fig 3 Excavator Arm Model 
Vol. 8, Issue 6, June 2021

DOI: $10.17148 / I A R J S E T .2021 .8642$

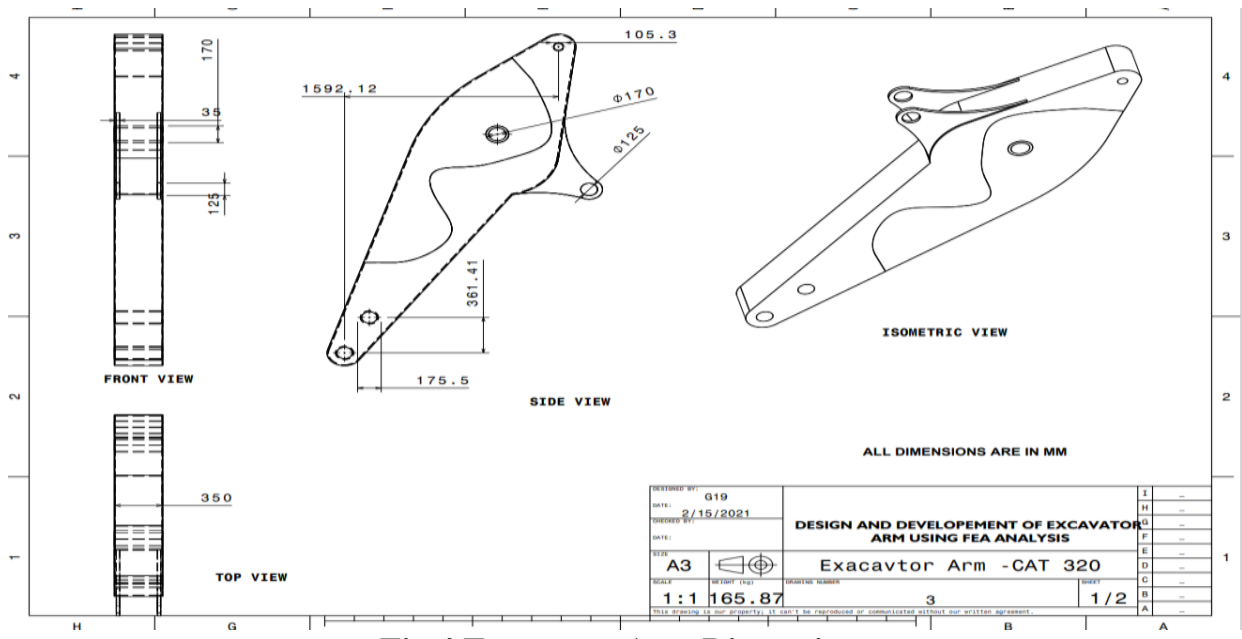

Fig.4.Excavator Arm Dimensions

\section{Materials Used}

1.Excavator Arm

For the construction of the excavator in its original configuration, the use of the classic S355 UNI EN 10025-3 construction steel is assumed.Table shows the characteristics of the materials used for the study and design of the excavator arms.

\begin{tabular}{l|l}
\multicolumn{2}{c}{ Structural Steel } \\
\hline Young's Modulus & $2 \times 105 \mathrm{MPa}$ \\
\hline Poisson's Ratio & 0.3 \\
\hline Density & $7.85 \mathrm{e}-006 \mathrm{~kg} / \mathrm{mm}^{3}$ \\
\hline Thermal Expansion & $1.2 \mathrm{e}-005 \mathrm{l} /{ }^{\circ} \mathrm{C}$ \\
\hline Tensile Yield Strength & $250 . \mathrm{MPa}$ \\
\hline Compressive Yield Strength & $250 . \mathrm{MPa}$ \\
\hline $\begin{array}{l}\text { Tensile Ultimate Strength } \\
\text { Table 1: Physical properties of Arm Material }\end{array}$
\end{tabular}

E. Excavator Assembly

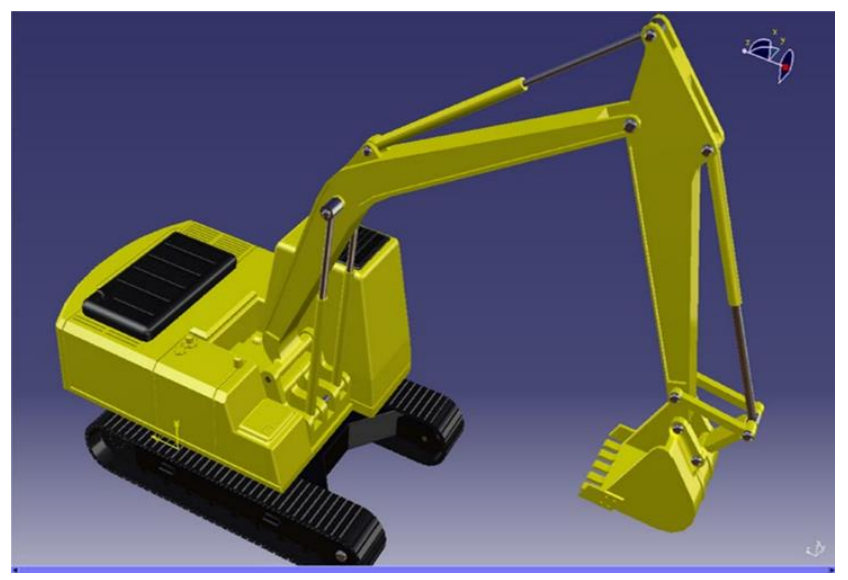

Fig.5 Assembly of an Excavator

\section{F. Meshing of assembly, applying connections etc. in ANSYS.}

In this section calculation for the static force analysis of the bucket and arm excavator for the condition in which the mechanism produces the maximum breakout force has been done. The most critical condition in the force analysis, is the maximum breakout force condition, as it produces the highest breakdown force and due to this condition, the force analysis is done and will be used as a boundary condition for static FEA.The free body diagram of bucket and arm, with directions and magnitudes of the forces are explained in this section. 


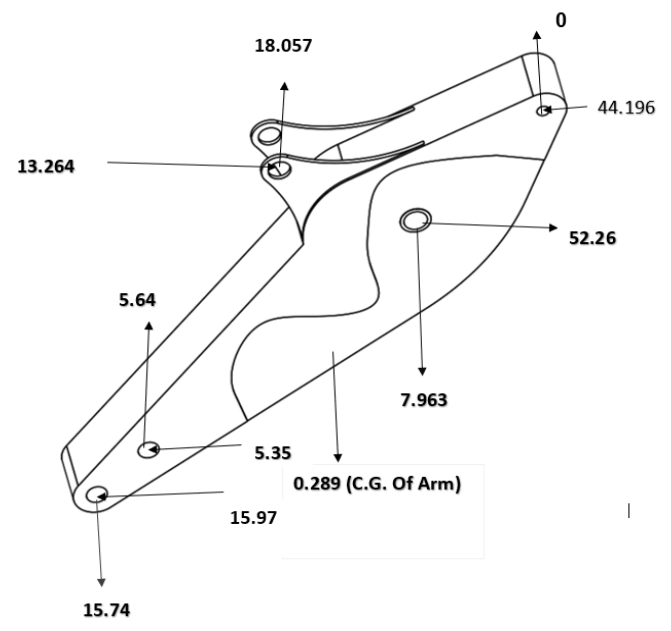

Fig.6: Free body diagram of arm of excavator

\begin{tabular}{|c|c|c|}
\hline Joint & $\begin{array}{c}\text { Horizontal } \\
\text { Component }\end{array}$ & $\begin{array}{c}\text { Vertical } \\
\text { Component }\end{array}$ \\
\hline A1 & -15.97 & -15.74 \\
\hline A2 & -5.35 & 5.64 \\
\hline A3 & 52.26 & -6.963 \\
\hline A4 & 13.264 & 18.057 \\
\hline A5 & 44.196 & 0 \\
\hline
\end{tabular}

Table 7. Forces on arm

\section{G. Analysis}

Particularly analysis is carried out in three stages by performing various operations in software.

1.) Preprocessing

a) Meshing

In this stage, igs file is imported to the meshing software like Hypermesh. The CAD data of the arm structure is imported and the surfaces were created and meshed.

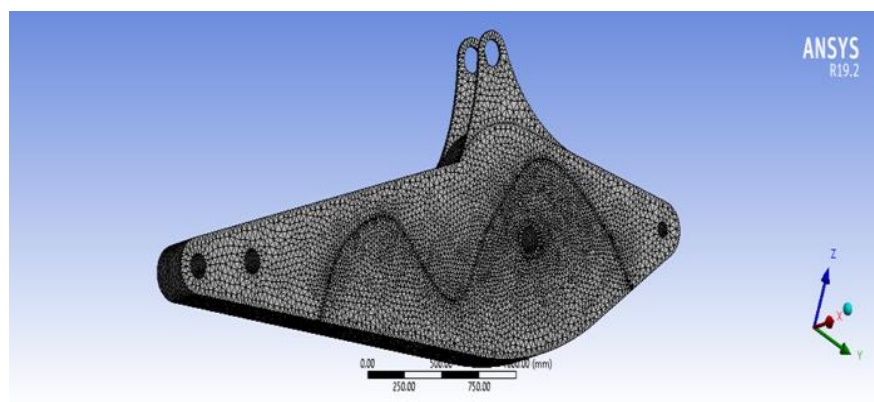

Fig.7. tetra-hedral meshing on arm of excavator

Number of nodes: 132891

Number of elements:66049 Element size $=20 \mathrm{~mm}$ 


\section{International Advanced Research Journal in Science, Engineering and Technology}

Vol. 8, Issue 6, June 2021

DOI: $10.17148 /$ IARJSET.2021.8642

\section{b) Solution and Post-processing}

After that, the meshed and boundary conditions applied object is imported to the solver section. After applying run in the solver software. The analysis process starts immediately.

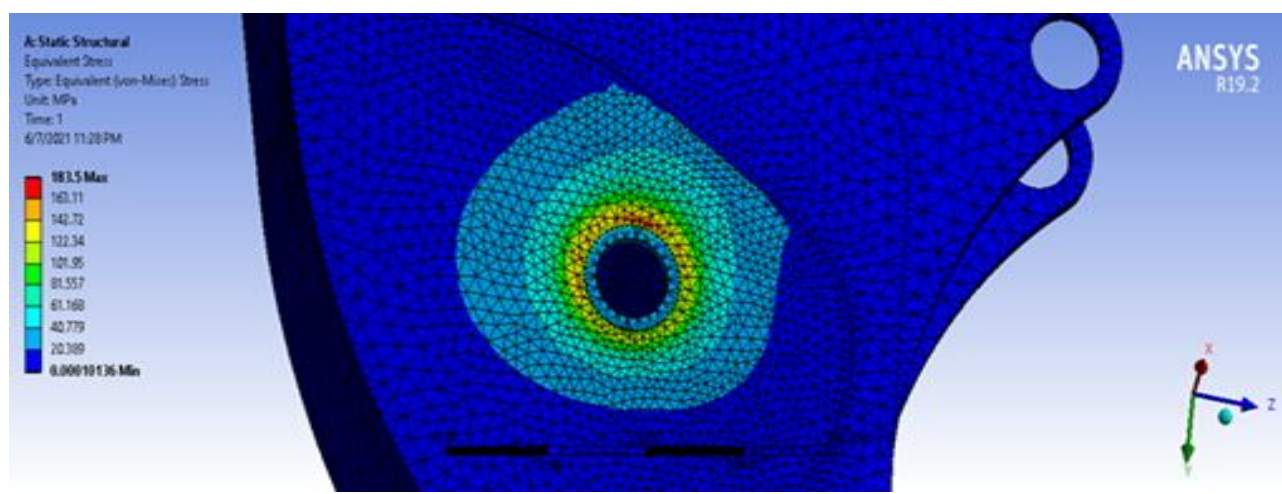

Fig.8: Von-mises stress at joints of excavator arm

The stress value determined for excavator arm is $234.45 \mathrm{~N} / \mathrm{mm} 2$ which is well below the critical value. Hence, design is safe.

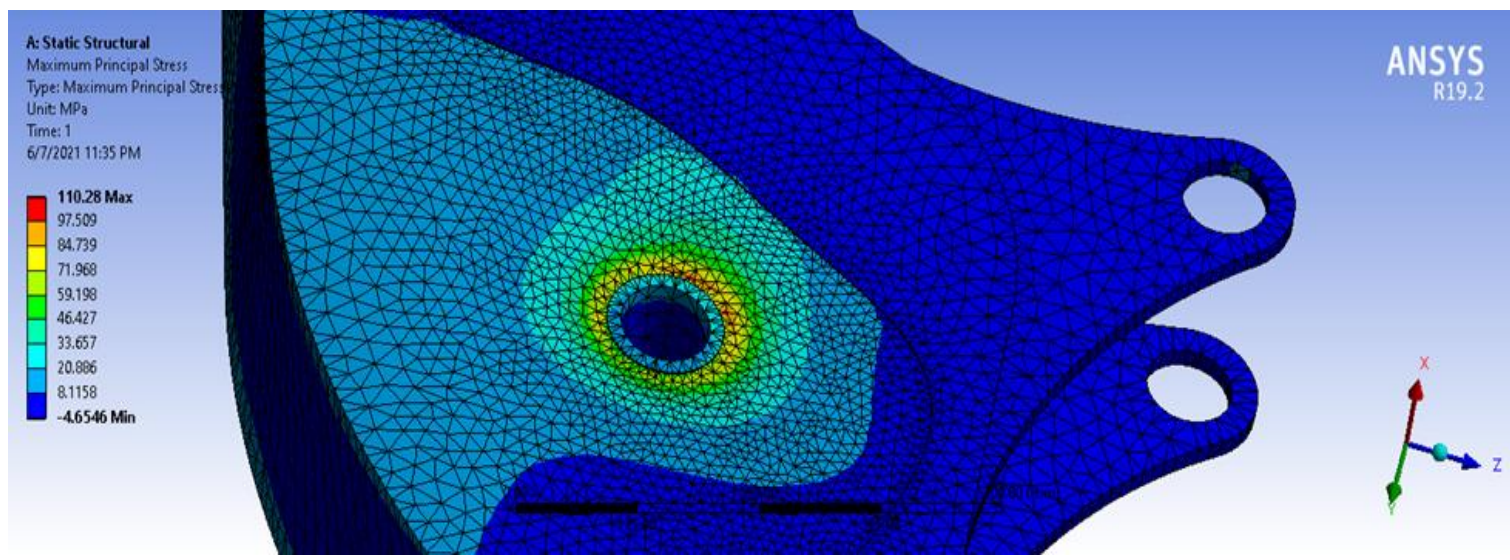

Fig 8. Maximum Principal Stress

The max stress obtained is $183.5 \mathrm{MPa}$ which means the design is safe as the yield strength of the arm is $250 \mathrm{MPa}$.The maximum Principal stress found was $110.28 \mathrm{MPa}$

From the analysis following comparison stresses and deformation are observed.

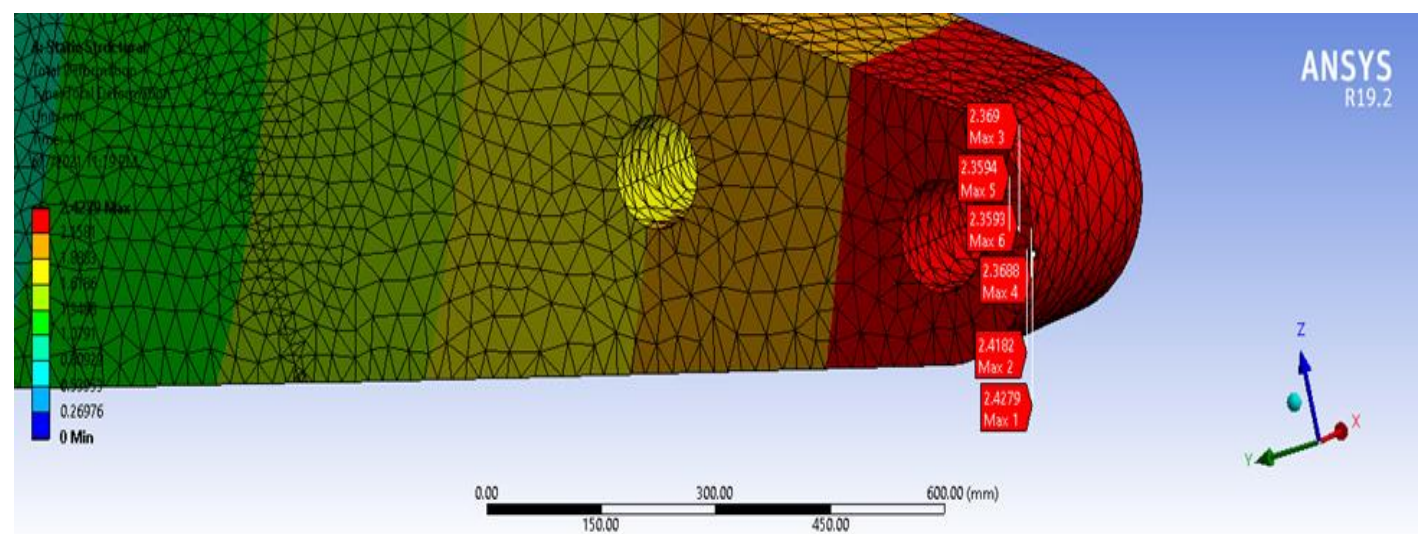

Fig.9 Total Deformation

The Total Deformation was observed to be $2.42 \mathrm{~mm}$ which is much lesser thus the minimum plate thickness of any subpart of the arm i.e. $35 \mathrm{~mm}$.Hence the design is also safe in terms of deformation Analysis results. 


\section{International Advanced Research Journal in Science, Engineering and Technology}

Vol. 8, Issue 6, June 2021

DOI: $10.17148 /$ IARJSET.2021.8642

\section{CONCLUSION AND FUTURE SCOPE}

\section{Conclusion}

1. The forces on the excavator are calculated and the forces flowing to excavator arm are determined.

2. The excavator arm is modelled and analysed using software.

3. The analysed part shows there is a scope for optimization.

4. The FEM results and experimental results are made a comparable study and the validation shows close variance.

5. From comparison of weight of existing model and optimized model it is seen that Overall weight reduction of $5 \%$ approximately has been achieved.

\section{Future scope}

Although Finite Element analysis is a user-friendly process, a lot more can be done in this subject. This will also help the future inventions for the better improvement in this. Finite element analysis for state of Boom, Arm, Buckets while at rest or moving and at its numerous degrees of freedom can play a vital role for future researchers to study, as this will be easy to study and therefore obtain a long lifecycle without breakdown for large machinery such as Excavators.

\section{ACKNOWLEDGMENT}

We take opportunity to express us deep sense of gratitude and respect to our guide Dr. Anil Sahu. It was great pleasure for us to have worked under his valuable and endless guidance, technical assistance and constant encouragement, which inspired us. We thank him for the confidence he showed and developed in us.

Also, we would like to thanks to our other teaching department and our respected HOD Dr. R. R. Arakerimath sir for encouraging us and providing us this golden opportunity.

Lastly, we would like to thanks all the people who had helped us in this research directly or indirectly.

\section{REFERENCES}

[1]. Mehta Gaurav K, "Design and Development of an Excavator Attachment” M. tech Dissertation Thesis, Nirma University, Institute of Technology, Ahmedabad, May 2008, pp. 1

[2]. Bhaveshkumar P. Patel, Dr. J. M. Prajapati, "Soil-Tool Interaction as a Review for Digging Operation of Mini Hydraulic Excavator", International Journal of Engineering Science and Technology, Vol. 3 No. 2, February 2011, 894-901.

[3]. Nareshkumar N. Oza, "Finite Element Analysis and Optimization of an Earthmoving Equipment Attachment - Backhoe", M. tech Dissertation Thesis, Nirma University, Institute of Technology, Ahmedabad, May

[4]. Luigi Solazzi, "Design of aluminium boom and arm for an excavator", Journal of Terramechanics, Elsevier, Vol. 47, 2010, pp. 201-207.

[5]. Rahul Mishra and Vaibhav Dewangan (2013), "Optimization of Component of Excavator Bucket", IJSRET, Vol. 2. No. 2, pp. 076-078.

[6]. Bhaveshkumar P Patel and Prajapati J M (2012), "Evaluation of Resistive Force Using Principle of Soil Mechanics for Mini Hydraulic Backhoe Excavator", International Journal of Machine Learning and Computing, Vol. 2, No. 4.

[7]. Bhaveshkumar P Patel and Prajapati J M (2011), “A Review on FEA and Optimization of Backhoe Attachment in Hydraulic Excavator”, IACSIT International Journal of Engineering and Technology, Vol. 3, No. 5.

[8]. Jakub Gottvald (2012), “Analysis of Vibrations of Bucket Wheel Excavator Schrs1320 During Mining Process”, FME Transactions, Vol. 40, pp. $165-170$.

[9]. Y. B. Kim, J. Ha, H. Kang, P. Y. Kim, J. Park, and F. C. Park, "Dynamically optimal trajectories for earthmoving excavators," Automation in Construction, vol. 35, pp. 568-578, 2013.

[10]. F. G. Flores, A. Kecskem' ethy, and A. P"ottker, "Workspace analysis and maximal force calculation of a face-shovel excavator using kinematical transformers," in Proceedings of the 12th IFToMM World Congress in Mechanism And Machine Science, pp. 375-381, Besancon, France, June 2007

[11]. J. Chen, Z. Zou, and X. Pang, "Digging performance characterization for hydraulic excavator considering uncertainty during digging operation," Proceedings of the Institution of Mechanical Engineers, Part C: Journal of Mechanical Engineering Science, vol. 232, no. 5, pp. 857-871, 2018.

[12]. S. Koji, O. Akira, and F. Kozo, "Development of multi-objective six-sigma approach for robust design optimization," Journal of Aerospace Computing, Information, and Communication, vol. 8, no. 5, pp. 215-233, 2008

[13]. S. Sundaresan, K. Ishii, and D. R. Houser, “A robust optimization procedure with variations on design variables and constraints," Engineering Optimization, vol. 24, no. 2, pp. 101-117, 2007 